\title{
Prescribing 6-weeks of running training using parameters from a self- paced maximal oxygen uptake protocol
}

\author{
James S. Hogg ${ }^{1}$ D . James G. Hopker ${ }^{1} \cdot$ Sarah L. Coakley ${ }^{2} \cdot$ Alexis R. Mauger $^{1}$
}

Received: 4 October 2017 / Accepted: 17 January 2018 / Published online: 12 February 2018

(c) The Author(s) 2018. This article is an open access publication

\begin{abstract}
Purpose The self-paced maximal oxygen uptake test (SPV) may offer effective training prescription metrics for athletes. This study aimed to examine whether SPV-derived data could be used for training prescription.

Methods Twenty-four recreationally active male and female runners were randomly assigned between two training groups: (1) Standardised (STND) and (2) Self-Paced (S-P). Participants completed 4 running sessions a week using a global positioning system-enabled (GPS) watch: $2 \times$ interval sessions; $1 \times$ recovery run; and $1 \times$ tempo run. STND had training prescribed via graded exercise test (GXT) data, whereas S-P had training prescribed via SPV data. In STND, intervals were prescribed as $6 \times 60 \%$ of the time that velocity at $\dot{V} \mathrm{O}_{2 \max }\left({ }_{\mathrm{v}} \dot{V} \mathrm{O}_{2 \max }\right)$ could be maintained $\left(T_{\text {max }}\right)$. In S-P, intervals were prescribed as $7 \times 120 \mathrm{~s}$ at the mean velocity of rating of perceived exertion $20\left({ }_{\mathrm{v}}\right.$ RPE20). Both groups used 1:2 work:recovery ratio. Maximal oxygen uptake $\left(\dot{V} \mathrm{O}_{2 \max }\right),{ }_{\mathrm{v}} \dot{V} \mathrm{O}_{2 \max }, T_{\max , \mathrm{v}} \mathrm{RPE} 20$, critical speed (CS), and lactate threshold (LT) were determined before and after the 6-week training.

Results STND and S-P training significantly improved $\dot{V} \mathrm{O}_{2 \max }$ by $4 \pm 8$ and $6 \pm 6 \%$, CS by $7 \pm 7$ and $3 \pm 3 \%$; LT by $5 \pm 4 \%$ and $7 \pm 8 \%$, respectively (all $P<.05$ ), with no differences observed between groups.

Conclusions Novel metrics obtained from the SPV can offer similar training prescription and improvement in $\dot{V} \mathrm{O}_{2 \max }$, CS and LT compared to training derived from a traditional GXT.
\end{abstract}

Keywords Recreational runners $\cdot$ Running performance $\cdot$ Critical speed $\cdot$ Endurance training $\cdot$ Lactate threshold

$\begin{array}{ll}\text { Abbreviations } \\ \text { ANOVA } & \text { Analysis of variance } \\ \text { CS } & \text { Critical speed } \\ \text { GPS } & \text { Global positioning system } \\ \text { GXT } & \text { Graded exercise test } \\ \text { HR }_{\max } & \text { Maximal heart rate } \\ \text { LT } & \text { Lactate threshold } \\ \text { LT1 } & \text { Lactate threshold 1 } \\ \text { LT2 } & \text { Lactate threshold } 2 \\ \text { RER } & \text { Respiratory exchange ratio } \\ \text { RER }_{\max } & \text { Maximal respiratory exchange ratio }\end{array}$

Communicated by Peter Krustrup.

James S. Hogg

J.Hogg-580@kent.ac.uk

1 Endurance Research Group, Faculty of Science, School of Sport and Exercise Sciences, University of Kent, Chatham Maritime, Chantam ME4 4AG, Kent, UK

2 Department of Sport and Exercise Sciences, University of Chichester, Chichester, UK

\begin{tabular}{|c|c|}
\hline STND & Standardised \\
\hline S-P & Self-paced \\
\hline SPV & Self-paced $\dot{V} \mathrm{O}_{2 \max }$ test \\
\hline $\mathrm{T}_{\max }$ & Time in which ${ }_{v} \dot{V} \mathrm{O}_{2 \max }$ can be maintained \\
\hline $\mathrm{V}_{\text {Emax }}$ & Maximal minute ventilation \\
\hline $\mathrm{VCO}_{2}$ & Carbon dioxide production \\
\hline$\dot{V} \mathrm{O}_{2 \max }$ & Maximal oxygen uptake \\
\hline${ }_{\mathrm{v}} V \mathrm{O}_{2 \max }$ & Velocity at $V \mathrm{O}_{2 \max }$ \\
\hline
\end{tabular}

\section{Introduction}

The graded exercise test (GXT) is a globally recognised test which offers valuable information on key aerobic parameters such as maximal oxygen uptake $\left(\dot{V} \mathrm{O}_{2 \max }\right)$, and can be used to prescribe training for both elite athletes, and recreational exercisers. Recently, a novel approach to the traditional GXT has been proposed, termed the self-paced $\dot{V} \mathrm{O}_{2 \max }$ test (SPV), which consists of $5 \times 2$ min stages where speed or power is freely adjusted by the participant based on rating of perceived exertion (RPE) (Mauger and Sculthorpe 2012; 
Borg 1982). The SPV has been applied across a wide range of exercise modalities and ergometry despite its relative infancy (Mauger and Sculthorpe 2012; Chidnok et al. 2013; Straub et al. 2014; Hogg et al. 2015; Jenkins et al. 2017b; Lim et al. 2016; Scheadler and Devor 2015).

The general consensus from published research to date suggests that the SPV provides comparable $\dot{V} \mathrm{O}_{2 \max }$ values to the GXT (Chidnok et al. 2013; Hogg et al. 2015; Lim et al. 2016; Scheadler and Devor 2015; Straub et al. 2014; Faulkner et al. 2015; Hanson et al. 2016), however, the methodological differences and contrasting populations used may make direct comparisons between studies challenging. Higher $\dot{V} \mathrm{O}_{2 \max }$ values have been observed within the SPV test (Mauger and Sculthorpe 2012; Jenkins et al. 2017a, b; Astorino et al. 2015; Mauger et al. 2013), although all but one of these studies were cycling-based. However, the findings regarding differences in $\dot{V} \mathrm{O}_{2 \max }$ are less meaningful in terms of the utility of the test, with perhaps greater emphasis being placed on the practical advantages that the SPV has over the GXT. The problems associated with the GXT are well documented (Noakes 2008), such as the incremental fixed-intensity nature of the test, unknown test duration, and creating a test environment that is possibly unnatural and irrelevant for "real" sporting performance. It has, therefore, been put forward that the SPV may represent a paradigm shift in $\dot{V} \mathrm{O}_{2 \max }$ testing (Beltz et al. 2016), with self-paced protocols offering greater ecological validity due to the selfpaced and closed-loop nature, whilst also circumventing the issue of estimating the ramp-rate and starting work rate for the researcher or practitioner (Poole and Jones 2017).

The GXT offers additional metrics in addition to the measurement of $\dot{V} \mathrm{O}_{2 \max }$, such as the velocity at $\dot{V} \mathrm{O}_{2 \max }$ $\left.{ }_{(\mathrm{v}} \dot{V} \mathrm{O}_{2 \max }\right)$ and the time in which ${ }_{\mathrm{v}} \dot{V} \mathrm{O}_{2 \max }$ can be maintained $\left(T_{\max }\right)$. However, the identification of $T_{\max }$ requires an additional test which adds to the impracticality of the GXT. Nevertheless, $\dot{V} \mathrm{O}_{2 \max },{ }_{v} \dot{V} \mathrm{O}_{2 \max }$ and $T_{\max }$ have been shown to be useful and viable parameters in running training and performance (Billat and Koralsztein 1996; Esfarjani and Laursen 2007; Manoel et al. 2017; Smith et al. 2003) and can be used to prescribe training and assess training adaptation. If similar metrics for training prescription could be acquired from the SPV, in a singular test, it would demonstrate utility over and above traditional GXT assessment of $\dot{V} \mathrm{O}_{2 \max }$, especially as the SPV is an effective test for highly trained runners (Hogg et al. 2015; Scheadler and Devor 2015), and has good test-retest reliability (Jenkins et al. 2017a). In addition, the SPV has recently been validated as a field test (Lim et al. 2016), which increases its accessibility to a variety of athletes and coaches. Therefore, the ability to prescribe training from the SPV would enhance the value and utility of the test. As such, this study aimed to investigate whether training prescribed via novel metrics derived from the SPV could result in comparable improvements in key aerobic parameters as training formulated from traditional GXT variables.

\section{Materials and methods}

\section{Participants}

Twenty-four recreationally active male $(n=16)$ and female runners $(n=8)$ (Mean $\pm \mathrm{SD}$ : Age $=30 \pm 9$ years, body mass $=70 \pm 13 \mathrm{~kg}$, height $=172 \pm 9 \mathrm{~cm}$ ) volunteered to participate in this study. Sample size was estimated from power calculations (G-Power software, Franz Faul, Universitat Kiel, Germany) with mean and SD data from a similar training study (Esfarjani and Laursen 2007). The study was conducted with the approval of the Ethics Committee of the School of Sport and Exercise Sciences at the University of Kent (Approval reference: Prop01.2014-15). All participants who volunteered read and signed a form of written informed consent before participation.

\section{Exercise tests}

Participants were randomly allocated into two groups: 'Standardised' (STND) and 'Self-paced' (S-P). All participants completed a GXT, an SPV, a sub-maximal lactate threshold (LT) test on a motorised treadmill (Saturn, HP Cosmos, Nussdorf-Traunstein, Germany), and a critical speed (CS) test as part of baseline testing on three separate occasions over a 2 weeks period. The $\dot{V} \mathrm{O}_{2 \max }$ protocols were completed in a randomised order, 2-7 days apart and at the same time of day $( \pm 2 \mathrm{~h})$. Oxygen uptake $\left(\dot{V} \mathrm{O}_{2}\right)$ (Metalyzer 3BR2, Cortex, Lepzig, Germany) and heart rate (T31, Polar Electro Inc, New York, USA) were recorded for the duration of the testing protocol. The online gas analysis system was calibrated prior to every test in accordance with the manufacturer's guidelines. Before each test, participants performed a warm-up of their choice on the motorised treadmill, which was kept the same for all subsequent tests. The CS test was completed on an all-weather synthetic $400 \mathrm{~m}$ running track using the method outlined by Galbraith (2011). Briefly, this involved three runs at distances of 3600, 2400 and $1200 \mathrm{~m}$, each separated by $30 \mathrm{~min}$ recovery. For the lactate threshold (LT) protocol, participants completed 4 min stages on the treadmill with a capillary blood sample (Biosen C-Line, EKF Diagnostics, Barleben, Germany) taken at the end of each stage, with the velocity increasing by $1 \mathrm{~km} \mathrm{~h}^{-1}$ at the beginning of each stage. Starting speed was estimated based on each participant's individual fitness level. The test was terminated once lactate threshold 1 (LT1) and lactate threshold 2 (LT2) had been obtained, defined as blood lactate readings of 2 and $4 \mathrm{mmol} \mathrm{L}^{-1}$, respectively. Before each test, participants were instructed to maintain similar eating 
habits, abstain from alcohol (24 h) and caffeine ( $8 \mathrm{~h})$, and to avoid exhaustive or vigorous exercise $(48 \mathrm{~h})$. These conditions were verbally verified by the experimenter at each test visit. Following baseline testing all participants then undertook a 6 weeks field-based training program, consisting of two high intensity interval training sessions, one recovery run, and a tempo run per wk. Training sessions were either based on data from the SPV or GXT [depending on group allocation]. Participants completed either a GXT, or SPV mid-training [depending on group allocation] in the third week of the training programme. This test replaced one of the high intensity sessions for that week, with its sole purpose to recalibrate interval session intensity in both groups. All baseline tests were then repeated in the immediate twoweeks that followed the 6 weeks training intervention.

\section{Graded exercise test (GXT)}

The test commenced at a submaximal speed, gauged by the experimenter and subject, to help bring about volitional exhaustion within 8-12 min. Speed was increased by $1 \mathrm{~km} \mathrm{~h}^{-1}$ every 2 min and the test was terminated when participants reached volitional exhaustion. Treadmill gradient was set to $1 \%$. All previously described cardiorespiratory measures were recorded during this stage and participants continued until volitional exhaustion. 6-20 RPE (Borg 1982) was recorded $20 \mathrm{~s}$ before the end of each stage. Verbal encouragement was given throughout. ${ }_{\mathrm{v}} \dot{V} \mathrm{O}_{2 \max }$ was determined as the highest velocity that could be maintained for at least $30 \mathrm{~s}$ (Smith et al. 2003).

\section{Determination of $T_{\max }$}

For the GXT, the time that ${ }_{\mathrm{v}} \dot{V} \mathrm{O}_{2 \max }$ could be maintained $\left(T_{\max }\right)$ was measured in a separate bout of exercise (Smith et al. 2003). After a 20 min recovery (Nolan et al. 2014) following the GXT, participants warmed up on the treadmill at $60 \%_{\mathrm{v}} \dot{V} \mathrm{O}_{2 \max }$ for $5 \mathrm{~min}$. Participants were then allowed to stretch before remounting the treadmill with the speed being ramped up over $30 \mathrm{~s}$ until ${ }_{\mathrm{v}} \dot{V} \mathrm{O}_{2 \max }$ was reached. Participants were then asked to continue until volitional exhaustion. Heart rate and expired gas were recorded throughout this test.

\section{Self-Paced $\dot{V}_{2 \max }$ Test}

The SPV was completed as previously described by Hogg and colleagues (2015). Briefly, the SPV consisted of $5 \times 2$ min continuous stages with RPE increments of 11 , $13,15,17$ and 20. A zonal pacing system was used where the researcher would adjust the running speed based on the participant's positioning on the treadmill. Participants were informed about the self-pacing zones before the warm-up and then practiced moving between the zones after completing their individualised warm-up. Familiarisation of the 6-20 RPE scale and how to vary their speed according to a fixed RPE was provided via verbal explanation prior to the warm-up with specific emphasis given to considering their RPE for each given moment.

\section{Determination of $\dot{V} \mathrm{O}_{2 \max }$}

Averaging of $\dot{V} \mathrm{O}_{2}$ during GXT and SPV tests was performed over 30 s. $\dot{V} \mathrm{O}_{2 \max }$ in the GXT and SPV was defined as the highest $\dot{V} \mathrm{O}_{2}$ averaged for 30 s. A plateau in $\dot{V} \mathrm{O}_{2}$ during the GXT was accepted if the change in $\dot{V} \mathrm{O}_{2}$ during the highest $30 \mathrm{~s}$ average from each of the final two stages of the test were less than half of the normal stage-to-stage difference in $\dot{V} \mathrm{O}_{2}$ during the initial linear parts of the test for each subject (Beltrami et al. 2012). As an ancillary method to verify attainment of $\dot{V} \mathrm{O}_{2}$, secondary criteria were accepted when two of the following were attained: Heart rate (HR) within $10 \mathrm{bpm}$ of age-predicted maximum; Respiratory exchange ratio $(\mathrm{RER}) \geq 1.15$ and $\mathrm{RPE} \geq 17$.

\section{Training programme}

All participants completed two high-intensity interval sessions per week, along with a recovery run and a tempo run. This equated to four exercise sessions per week. Participants were free to schedule the sessions throughout each week but were encouraged to not complete interval sessions and tempo run on consecutive days. All sessions were completed using an assigned global positioning system (GPS) watch (310XT, Garmin International Inc, KS, USA), and training was logged in a training diary.

\section{STND Group}

For each interval session, participants completed 6 intervals at ${ }_{\mathrm{v}} \dot{V} \mathrm{O}_{2 \max }$ with duration determined as $60 \%$ of $T_{\max }$ (Smith et al. 2003). A 2:1 ratio was used to determine the recovery stage duration in-between each interval. Recovery run intensity was calculated as $60 \%$ of their maximal heart rate $\left(\mathrm{HR}_{\max }\right)$ obtained from the GXT. Participants were required to run for $30 \mathrm{~min}$. This session was included to help ensure participants would not be encouraged to supplement their program with additional training.

Tempo run intensity was determined from the submaximal LT test and participants were required to run at a velocity calculated as $50 \%$ between LT1 and LT2 for $30 \mathrm{~min}$.

\section{S-P group}

For each interval session, participants completed $7 \times 2$ min intervals at a velocity corresponding to the mean velocity 
completed during the final (RPE20) stage of the SPV. A 2:1 ratio was used to determine the recovery stage duration in-between each interval. The recovery run was the same as in the STND group, but intensity was calculated as $60 \%$ of their $\mathrm{HR}_{\max }$ obtained from the SPV.

Tempo run intensity was determined by calculating the ventilatory threshold (VT) via the V-Slope method from the $\dot{V} \mathrm{O}_{2}$ and $\dot{V} \mathrm{CO}_{2}$ data collected during the SPV (Beaver et al. 1986). The participants were then asked to run at an RPE that corresponded with the stage of the SPV in which the VT was achieved. The participants were asked to freely adjust their pacing to match the required RPE.

\section{Statistical analysis}

Prior to statistical analysis, data were checked and confirmed to be normally distributed. A paired samples $t$ test was performed to assess maximal value differences between protocols. Based on the achieved effect size, a post hoc power analysis demonstrated that the statistical power of the prepost $\dot{V} \mathrm{O}_{2 \max }$ comparison was 0.93 . To identify training responses for both training groups (group) and GXT and SPV protocols (protocol) for before and after training (timepoint) a mixed model analysis of variance (ANOVA) was used. Where no interaction effect was identified between a variable and protocol (GXT and SPV), the protocol was omitted from further analysis of training responses for that variable. Participants' CS were calculated from the field test using a linear distance-time model. Partial eta-squared $\left(\eta_{p}^{2}\right)$ was used to report effect sizes, and statistical significance was accepted when $P<.05$. All statistical tests were completed using SPSS version 24 (Chicago, IL, USA).

\section{Results}

\section{SPV vs. GXT protocol data}

\section{Incidence of $\dot{\mathrm{V}} \mathrm{O}_{2}$ plateau in GXT and SPV Protocols}

The average stage-to-stage increase in $\dot{V} \mathrm{O}_{2}$ for all participants was calculated as $393 \pm 21 \mathrm{~mL} \mathrm{~min}^{-1}$, so that a plateau phenomenon was defined as a change in $\dot{V} \mathrm{O}_{2} \leq 197 \pm 10 \mathrm{~mL}$. $\min ^{-1}$ (or relative $\dot{V} \mathrm{O}_{2} 2.8 \mathrm{~mL} \mathrm{~kg}^{-1} \mathrm{~min}^{-1}$ ), between the highest $30 \mathrm{~s}$ average obtained from each of the final two stages of the test for each participant. All participants achieved either a $\dot{V} \mathrm{O}_{2}$ plateau or satisfied secondary criteria across both GXT trials before and after training. Ninetythree percent of participants satisfied secondary criteria across both SPV trials before and after training.
Table 1 Mean \pm SD peak values for physiological and intensity variables recorded during both GXT and SPV protocols across both before and after training for all participants

\begin{tabular}{lcc}
\hline Variable & \multicolumn{2}{l}{ Protocol } \\
\cline { 2 - 3 } & \multicolumn{1}{l}{ GXT } & SPV \\
\hline$\dot{V} \mathrm{O}_{2 \max }\left(\mathrm{mL} \mathrm{kg}^{-1} \mathrm{~min}^{-1}\right)$ & $54 \pm 5.8$ & $54 \pm 0.7$ \\
$\mathrm{HR}_{\max }\left(\right.$ beats $\left.\mathrm{min}^{-1}\right)$ & $186 \pm 12$ & $184 \pm 11$ \\
$V_{\mathrm{Emax}}(\mathrm{L} \mathrm{min})$ & $135.4 \pm 29.4$ & $137.2 \pm 24.8$ \\
$\mathrm{RER}_{\max }$ & $1.15 \pm 0.02$ & $1.21 \pm 0.00^{*}$ \\
${ }_{\mathrm{V}} \mathrm{O}_{2 \max } /{ }_{\mathrm{v}} \mathrm{RPE} 20\left(\mathrm{~km} \mathrm{~h}^{-1)}\right.$ & $14.8 \pm 1.3$ & $15 \pm 1.5$ \\
$\mathrm{Mean} \mathrm{test} \mathrm{time}(\min )_{\mathrm{RPE}}$ & $11 \pm 1^{*}$ & $10 \pm 0$ \\
& $19 \pm 1$ & $20 \pm 0^{*}$ \\
\hline
\end{tabular}

*Denotes significant difference within the group for the given variable between pre and post testing $(P<.05)$

\section{Differences in test protocols}

Differences in test protocols for key variables for all participants are presented in Table 1. Pre and post-training data were combined to compare the GXT and SPV protocols. There were no significant differences in $\dot{V} \mathrm{O}_{2 \mathrm{max}}$ between the GXT and SPV protocols $(P=.578)$. Maximal RER $\left(\mathrm{RER}_{\max }\right)$ was significantly greater in the SPV compared to the GXT $(P<.001)$. There was no interaction effect between test protocol for either $\mathrm{HR}_{\max }$ or maximal minute ventilation $\left(V_{\text {Emax }}\right)(P=.212 ; P=.319$, respectively). Protocol duration was significantly longer in the GXT $(P<.001)$. RPE max $_{\text {was }}$ significantly greater in the SPV $(P<.001)$. There were no significant differences between the velocities associated with $\dot{V} \mathrm{O}_{2 \max }$ and $\operatorname{RPE} 20(P=.130)$.

\section{STND vs. S-P training data}

\section{Training prescription}

Total prescribed training duration over the 6 weeks period for both training groups was not significantly different $(P=.651)$. The STND had a prescribed total duration of $804 \pm 90$ min whilst the S-P had a prescribed total duration of $816 \pm 0 \mathrm{~min}$. There was no significant difference between the mean interval session duration for both STND and S-P $(37 \pm 8$ vs. $38 \pm 0 \mathrm{~min}$, respectively) $(P=.679)$.

\section{Responses to training}

Group data (pre- vs. post-training) are shown in Table 2. As outlined in the methods, participants were grouped into either S-P or STND, and conducted both an SPV and GXT before and after the training intervention. There was no interaction effect for protocol duration between time-point, protocol and group $\left(F_{1,22}=0.561, P=.462, \eta_{p}^{2}=0.025\right)$. As 
Table 2 Mean \pm SD maximal values for physiological and threshold variables recorded before and after training for both training groups

\begin{tabular}{|c|c|c|c|c|}
\hline \multirow[t]{3}{*}{ Variable } & \multicolumn{4}{|c|}{ Training group } \\
\hline & \multicolumn{2}{|c|}{ Standardised (STND) } & \multicolumn{2}{|c|}{ Self-Paced (S-P) } \\
\hline & Pre & Post & Pre & Post \\
\hline $\begin{array}{l}\dot{V} \mathrm{O}_{2 \max }\left(\mathrm{mL} \cdot \mathrm{kg}^{-1}\right. \\
\left.\min ^{-1}\right)\end{array}$ & $54 \pm 5.0$ & $56.3 \pm 6.2^{*}$ & $51.7 \pm 5.3$ & $54.8 \pm 5.7^{*}$ \\
\hline$V_{\text {Emax }}(\mathrm{L} / \mathrm{min})$ & $130.2 \pm 22.6$ & $134.7 \pm 20.4^{*}$ & $134.3 \pm 28.7$ & $141.5 \pm 29.0^{*}$ \\
\hline $\mathrm{HR}_{\max }$ (beats/min) & $190 \pm 13$ & $188 \pm 13$ & $181 \pm 13$ & $182 \pm 9$ \\
\hline $\begin{array}{l}\text { Critical speed } \\
\left(\mathrm{m} \mathrm{s}^{-1}\right)\end{array}$ & $3.47 \pm 0.03$ & $3.70 \pm 0.03 *$ & $3.47 \pm 0.04$ & $3.59 \pm 0.05^{*}$ \\
\hline LT1 $\left(\mathrm{km} \mathrm{h}^{-1}\right)$ & $10 \pm 1.2$ & $10.5 \pm 1.2^{*}$ & $9.7 \pm 1.5$ & $10.5 \pm 1.3^{*}$ \\
\hline LT2 $\left(\mathrm{km} \mathrm{h}^{-1}\right)$ & $11.7 \pm 1.2$ & $12.2 \pm 0.8^{*}$ & $11.1 \pm 1.8$ & $12.1 \pm 1.5^{*}$ \\
\hline
\end{tabular}

In the STND all data is provided via the GXT and by the SPV for the S-P

*Denotes significant difference within the group for the given variable between pre and post testing $(P<.05)$

shown in Fig. 1 and Table 2, there was an interaction effect between $\dot{V} \mathrm{O}_{2 \max }$ and time-point $\left(F_{1,22}=7.461, P=.012, \eta_{p}^{2}\right.$ $=0.253)$, however, there was no interaction effect observed between group and time-point $\left(F_{1,22}=0.003, P=.954, \eta_{p}^{2}\right.$ $=0.0001)$. Whilst there was an interaction effect between $V_{\text {Emax }}$ and time-point $\left(F_{1,22}=12.592, P=.002, \eta_{p}^{2}=0.364\right)$, there was no interaction effect between time-point and group $\left(F_{1,22}=0.001, \mathrm{P}=.981, \eta_{p}^{2}=0.0001\right)$. There was no interaction effect for $\mathrm{HR}_{\max }$ between time-point and group $\left(F_{1,22}=\right.$ 1.063, $P=.314, \eta_{p}^{2}=0.046$ )

There was an interaction effect between time-point and running velocity at ${ }_{\mathrm{v}} \mathrm{RPE} 20$ and ${ }_{\mathrm{v}} \dot{V} \mathrm{O}_{2 \max } F_{1,20}=5.800$, $P=.026, \eta_{p}^{2}=0.225$ ). As shown in Fig. 2 , for both groups there were no differences in ${ }_{\mathrm{v}} \dot{V} \mathrm{O}_{2 \max }$ and ${ }_{\mathrm{v}} \mathrm{RPE}_{20}$ before training $\left(14.3+1.3\right.$ vs. $14.3+1.7 \mathrm{~km} \mathrm{~h}^{-1}$, respectively), but ${ }_{\mathrm{v}} \mathrm{RPE} 20$ was greater than ${ }_{\mathrm{v}} \dot{V} \mathrm{O}_{2 \text { max }}$ after training $(15.7+1.3$ vs. $15.2+1.3 \mathrm{~km} \mathrm{~h}^{-1}$, respectively). CS improved in both groups $(P<.001)$ however there was no interaction effect between time-point and group $\left(F_{1,21}=3.006, P=.098, \eta_{p}^{2}\right.$ $=0.125)$. Similarly, LT1 and LT2 improved in both groups
$\left(F_{1,21}=14.637, P<.001, \eta_{p}^{2}=.411\right)$, however, there was no interaction effect between time-point and group $\left(F_{1,21}=\right.$ $\left.1.227, P=.281, \eta_{p}^{2}=.055\right)$.

\section{Discussion}

The primary finding of this study was that following a 6 weeks period of training, recreational runners' aerobic fitness and running performance was increased by a similar magnitude, regardless of whether SPV or GXT data were used to prescribe training. Specifically, $\dot{V} \mathrm{O}_{2 \max }$ in the STND group improved by $4 \%$, and by $6 \%$ in the S-P group. An improvement in $\dot{V} \mathrm{O}_{2 \max }$ in the region of $\sim 3 \%$ has previously been defined as a meaningful improvement in performance (Kirkeberg et al. 2010), as opposed to dayto-day variation. Previous literature has shown improvements in $\dot{V} \mathrm{O}_{2 \max }$ by $\sim 6 \%$ when training at $106 \%$ v $\dot{V} \mathrm{O}_{2 \max }$ (Franch et al. 1998) for similar training durations. However, in the aforementioned study the starting $\dot{V} \mathrm{O}_{2 \max }$ for the
Table 3 Training prescription for a representative subject in both training groups

\begin{tabular}{|c|c|c|c|c|}
\hline \multirow[t]{3}{*}{ Rep. Subject } & \multicolumn{4}{|c|}{ Training prescription } \\
\hline & \multicolumn{2}{|l|}{ Interval session $\times 2$} & \multirow{2}{*}{$\begin{array}{l}\text { Tempo run } \\
\text { Weeks 1-6 }\end{array}$} & \multirow{2}{*}{$\begin{array}{l}\text { Recovery run } \\
\text { Weeks } 1-6\end{array}$} \\
\hline & Weeks 1-3 & Weeks 4-6 & & \\
\hline STND & $\begin{array}{l}\text { Work: } 6 \times 167 \mathrm{~s} \\
\text { @ } 15 \mathrm{~km} \mathrm{~h}^{-1} \\
\text { Recovery: } \\
5 \times 334 \mathrm{~s} @ \\
8 \mathrm{~km} \mathrm{~h}^{-1}\end{array}$ & $\begin{array}{l}\text { Work: } 6 \times 141 \mathrm{~s} @ \\
16 \mathrm{~km} \mathrm{~h}^{-1} \\
\text { Recovery: } \\
5 \times 282 \mathrm{~s} @ \\
8 \mathrm{~km} \mathrm{~h}^{-1}\end{array}$ & $\begin{array}{l}30 \min @ \\
11.3 \mathrm{~km} \mathrm{~h}^{-1}\end{array}$ & $\begin{array}{l}30 \text { min @ } \\
115 \text { bpm }\end{array}$ \\
\hline S-P & $\begin{array}{l}\text { Work: } 7 \times 120 \mathrm{~s} \\
\text { @ } 15.6 \mathrm{~km} \mathrm{~h}^{-1} \\
\text { Recovery: } \\
6 \times 240 \mathrm{~s} @ \\
8 \mathrm{~km} \mathrm{~h}^{-1}\end{array}$ & $\begin{array}{l}\text { Work: } 7 \times 120 \mathrm{~s} @ \\
16.3 \mathrm{~km} \mathrm{~h}^{-1} \\
\text { Recovery: } \\
6 \times 240 \mathrm{~s} @ \\
8 \mathrm{~km} \mathrm{~h}^{-1}\end{array}$ & 30 min @ RPE13 & $\begin{array}{l}30 \text { min @ } \\
114 \text { bpm }\end{array}$ \\
\hline
\end{tabular}

$S T N D$ standardised group, $S$ - $P$ self-paced training group 


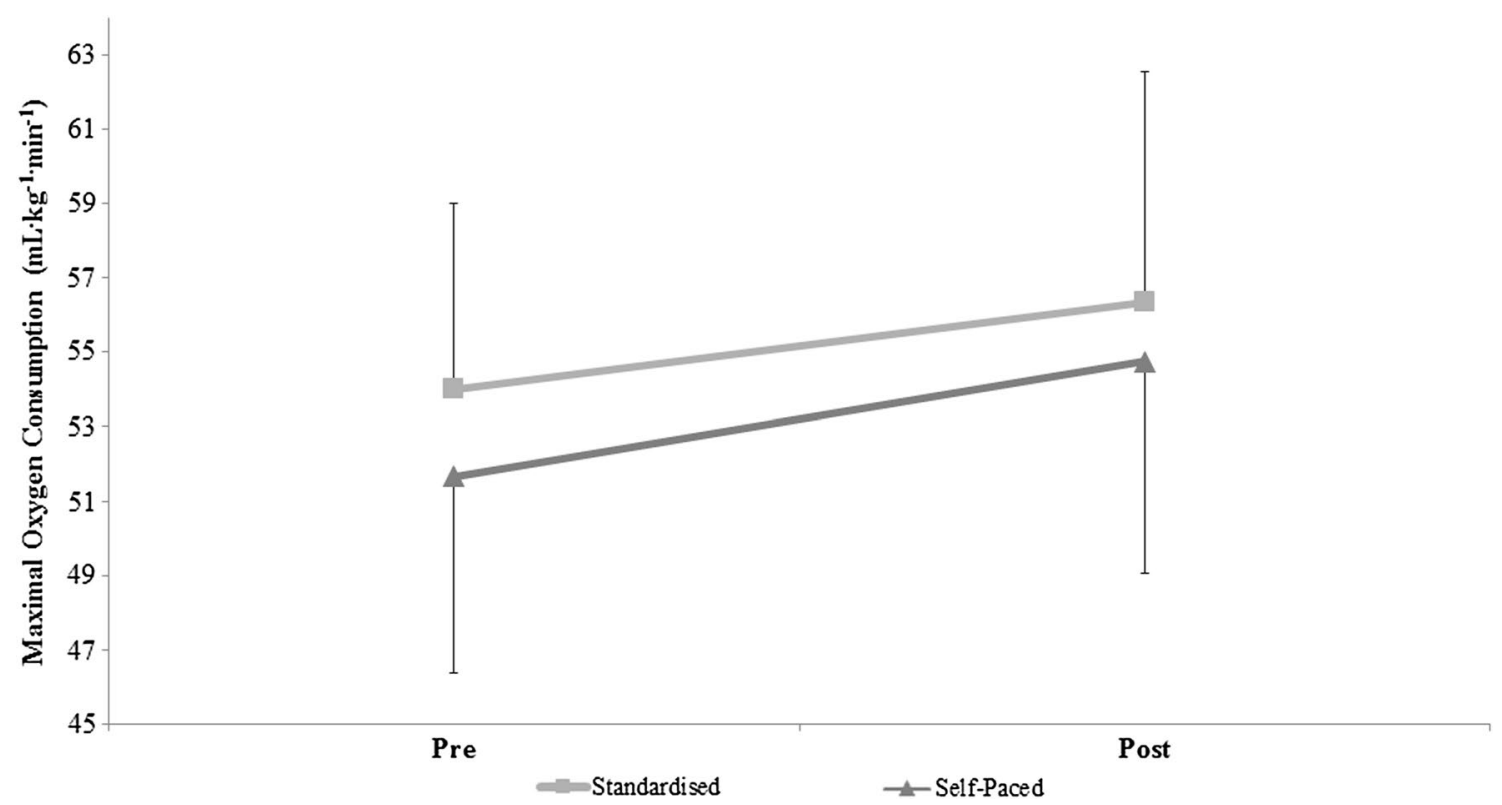

Fig. 1 Mean \pm SD Differences in $\mathrm{VO}_{2 \max }$ between the STND and S-P training groups before and after training

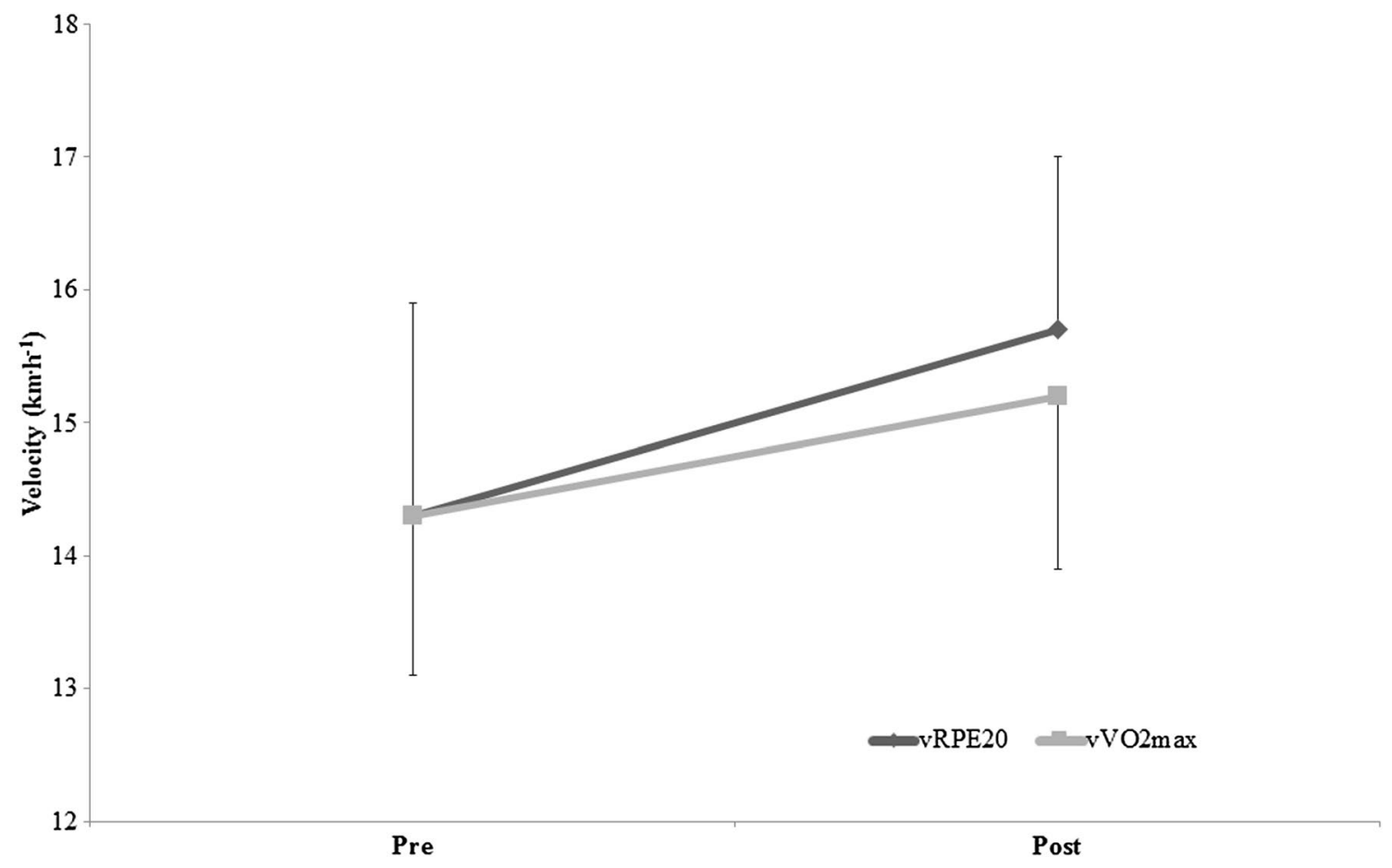

Fig. 2 Mean \pm SD Differences in the velocities ${ }_{v} \dot{V} \mathrm{O}_{2 \max }$ and ${ }_{\mathrm{v}} \mathrm{RPE} 20$ for all participants for before and after training

participants were significantly lower than those reported in the current study, which may suggest a greater level of trainability for $\dot{V} \mathrm{O}_{2 \max }$ (Swain and Franklin 2002) compared with the participants in the current study. Athletes of slightly higher training status' than those in the current study achieved little to no improvements in $\dot{V} \mathrm{O}_{2 \max }$ over
4-6 weeks of similar intensity training (Manoel et al. 2017; Smith et al. 2003; Denadai et al. 2006), but did show significant improvements in LT and 3-10 km running performance. Similar running programmes utilising interval training have also produced improvements in CS (Esfarjani and Laursen 2007). This is supported by the findings of the current study 
that in both STND and S-P, CS improved by 7 and 3\%, respectively. For LT1 and LT2, STND improved by 5 and $3 \%$ and S-P improved by 7 and $8 \%$.

An important finding of this study is that the novel training parameter extracted from the SPV, ' ${ }_{\mathrm{v}}^{\mathrm{RPE} 20}$ ', is effective at prescribing running intensity for interval training. The ${ }_{\mathrm{v}} \dot{V} \mathrm{O}_{2 \max }$ for the STND before and after training was $14.3 \pm 0.9$ vs. $15.2 \pm 1.0 \mathrm{~km} \mathrm{~h}^{-1}$ compared to the S-P's ${ }_{\mathrm{v}} \mathrm{RPE}_{20}$ of $14.2 \pm 1.9$ vs. $15.7 \pm 1.9 \mathrm{~km} \mathrm{~h}^{-1}$, respectively. It is likely that the ${ }_{\mathrm{v}} \mathrm{RPE} 20$ may reflect a speed between ${ }_{\mathrm{v}} \dot{V} \mathrm{O}_{2 \max }$ and the maximal velocity achieved in a GXT $\left(V_{\max }\right) \cdot V_{\max }$ has recently been shown to be as beneficial as ${ }_{\mathrm{v}} \dot{V} \mathrm{O}_{2 \max }$ for exercise prescription (Manoel et al. 2017), and like ${ }_{\mathrm{v}} \mathrm{RPE} 20$ is simple to calculate. Moreover, ${ }_{\mathrm{V}} \mathrm{RPE} 20$ has been shown to be repeatable regardless of the pacing strategy adopted during this final stage (Hanson et al. 2017). This should be reason to encourage further investigation to assess the potential of ${ }_{v}$ RPE20 in training prescription and its suitability as a performance parameter.

As the aim of the study was to investigate whether SPVderived training parameters could offer similar improvements in aerobic fitness compared to GXT prescribed training, it was important that training prescription was similar between groups in both intensity and duration. To calculate interval duration for the STND, 60\% $T_{\max }$ was used. Setting interval duration at $60 \%$ of an individual's $T_{\max }$ has been shown to produce significant improvements in aerobic parameters and 3-10 km running performance (Esfarjani and Laursen 2007; Manoel et al. 2017; Smith et al. 2003). In the study by Smith and colleagues (2003), 60\% $T_{\max }$ resulted in an average interval duration of $6 \times 133.4 \pm 4.1 \mathrm{~s}$. This equated to $\sim 13 \mathrm{~min}$ of high intensity effort per interval session. In the current study, 7 intervals at $120 \mathrm{~s}$ [which also matched the stage duration of the SPV] resulted in $\sim 14$ min of high intensity effort, ensuring it was comparable to the STND group (See Table 3). Durations of 2 min have been shown to elicit responses closer to $\dot{V} \mathrm{O}_{2 \max }$ compared to shorter intervals (O'Brien et al. 2008). Longer interval work periods may have resulted in a greater $\dot{V} \mathrm{O}_{2 m a x}$ improvement (Esfarjani and Laursen 2007; O'Brien et al. 2008; Seiler and Sjursen 2002) but also significantly increased the interval duration. As a consequence, the mean prescribed training duration for each interval session over the 6 weeks training period was similar between groups $(37 \pm 8$ vs. $38 \pm 0$ min for STND and S-P, respectively). Total training time over the 6-week period was also similar ( $804 \pm 90$ vs. $816 \pm 0 \mathrm{~min}$, for STND and S-P, respectively).

The similar $\dot{V} \mathrm{O}_{2 \max }$ found between both protocols in this study is in line with previous research (Chidnok et al. 2013; Hogg et al. 2015; Lim et al. 2016; Scheadler and Devor 2015; Straub et al. 2014; Faulkner et al. 2015; Hanson et al. 2016). Even though test duration was significantly longer in the GXT, the test still fell within the recommended duration of 8-12 min (Yoon et al. 2007), and the ${ }_{\mathrm{v}} \dot{V} \mathrm{O}_{2 \max }$ achieved was not significantly different between protocols. Interestingly, $\mathrm{RER}_{\max }$ was significantly higher in the SPV, which has been observed in some (Mauger and Sculthorpe 2012; Hogg et al. 2015; Jenkins et al. 2017b), but not all previous SPV literature (Lim et al. 2016; Straub et al. 2014; Faulkner et al. 2015; Astorino et al. 2015). Consequently, no consensus on whether the SPV produces a higher RER max $_{\text {can }}$ be currently drawn. However, the authors speculate that this potential difference in $\mathrm{RER}_{\max }$ may be due to the higher peak velocities experienced in the SPV compared to the GXT, indicative of a greater anaerobic contribution towards the end of the test. This is supported by the recent work of Hanson and colleagues (2017) who found, when comparing two SPV trials with different RPE20 pacing strategies, that RER $_{\text {max }}$ was significantly greater in the SPV that adopted the more aggressive pacing strategy.

\section{Conclusions}

The ability to prescribe training for recreationally active males and females via SPV-derived parameters offers coaches and athletes valuable alternatives to traditional methods. Prescribing training via the SPV is as effective but more time-economical. Specifically, the same level of improvement in key aerobic fitness parameters can be obtained when training is set via novel training parameters collected from a single 10 min SPV test compared to that achieved using a GXT and a mandatory additional test to acquire $T_{\max }$ data. This alone may make the SPV more attractive to athletes and coaches, however, recent research regarding a field based SPV (Lim et al. 2016) may emphasise this further. Whilst a field-based SPV has been shown to produce a valid directly measured $\dot{V} \mathrm{O}_{2 \max }$, future research should investigate whether $\dot{V} \mathrm{O}_{2 \max }$ can be accurately estimated from the field based SPV. If so, athletes and coaches would then be able to utilize a single 10 min test on an athletics track, without expensive equipment, that would offer accurate $\dot{V} \mathrm{O}_{2 \text { max }}$ estimation and data for effective training prescription. Therefore, the current findings demonstrate that training parameters derived from the SPV protocol can be used to prescribe effective running training that is similarly effective to training prescribed from GXT-derived parameters. Consequently, in the group that was prescribed training using SPV-derived parameters, $\dot{V} \mathrm{O}_{2 \max }$, LTs and CS showed similar improvements compared to runners who were prescribed training via ${ }_{\mathrm{v}} \dot{\mathrm{V}} \mathrm{O}_{2 \max }$ and LT zones, with training durations and intensities suitably similar between groups throughout training. 
Acknowledgements Adam Hart, Francesca Waters, Marcus Cram, and Stewart Clayton for their assistance with data collection.

Author contribution statement JSH and LM conceived and designed research. JSH and SLC recruited participants and conducted data collection. JSH, LM, and JGH analysed data. JSH wrote manuscript. All authors read and approved the manuscript.

\section{Compliance with ethical standards}

Conflict of interest The authors declares that they have no conflict of interest.

Ethical approval All procedures performed in studies involving human participants were in accordance with ethical standards of the institutional and/or national research committee and with the 1964 Helsinki declaration and its later amendments or 467 comparable ethical standards.

Open Access This article is distributed under the terms of the Creative Commons Attribution 4.0 International License (http://creativeco mmons.org/licenses/by/4.0/), which permits unrestricted use, distribution, and reproduction in any medium, provided you give appropriate credit to the original author(s) and the source, provide a link to the Creative Commons license, and indicate if changes were made.

\section{References}

Astorino TA, McMillan DW, Edmunds RM, Sanchez E (2015) Increased cardiac output elicits higher $V \mathrm{O}_{2 \max }$ in response to selfpaced exercise. Appl Physiol Nutr Metab 40(3):223-229

Beaver W, Wasserman K, Whipp B (1986) A new method for detecting anaerobic threshold by gas exchange. J Appl Physiol 60(6):2020-2027

Beltrami FG, Froyd C, Mauger AR, Metcalfe AJ, Marino F, Noakes TD (2012) Conventional testing methods produce submaximal values of maximum oxygen consumption. Br J Sports Med 46(1):23 - 9

Beltz NM, Gibson AL, Janot JM, Kravitz L, Mermier CM, Dalleck LC (2016) Graded exercising testing protocols for the determination of $V \mathrm{O}_{2 \mathrm{max}}$ : Historical perspectives, progress, and future considerations. J Sports Med https://doi.org/10.1155/2016/3968393

Billat VL, Koralsztein J-P (1996) Significance of the velocity at $V \mathrm{O}_{2 \max }$ and time to exhaustion at this velocity. Sports Med 22(2):90-108

Borg GAV (1982) Psychophysical bases of perceived exertion. Med Sci Sports Exerc 14(5):377-381

Chidnok W, Dimenna FJ, Bailey SJ et al (2013) $\mathrm{VO}_{2 \max }$ is not altered by self-pacing during incremental exercise. Eur J Appl Phys 113(2):529-539

Denadai BS, Ortiz MJ, Greco CC, Mello MT De (2006) Interval training at 95 and $100 \%$ of the velocity at $V \mathrm{O}_{2 \max }$ : Effects on aerobic physiological indexes and running performance. Appl Physiol Nutr Metab 31(6):737-743

Esfarjani F, Laursen PB (2007) Manipulating high-intensity interval training: Effects on $\mathrm{VO}_{2 \max }$, the lactate threshold and $3000 \mathrm{~m}$ running performance in moderately trained males. J Sci Med Sport 10(1):27-35

Faulkner J, Mauger AR, Woolley B, Lambrick D (2015) The efficacy of a self-paced $V \mathrm{O}_{2 \max }$ test during motorized treadmill exercise. Int J Sports Physiol Perform 10(1):99-105

Franch J, Madsen K, Djurhuus MS, Pedersen PK (1998) Improved running economy following intensified training correlates with reduced ventilator demands. Med Sci Sport Exerc 30(8):1250-1256
Galbraith A (2011) A novel field test to determine critical speed. J Sports Med Doping Stud 1(1):1-4

Hanson NJ, Scheadler CM, Lee TL, Neuenfeldt NC, Michael TJ, Miller MG (2016) Modality determines $V \mathrm{O}_{2 \max }$ achieved in self-paced exercise tests: validation with the Bruce protocol. Eur J Appl Physiol 116(7):1313-1319

Hanson NJ, Reid CR, Cornwell KM, Lee TL, Scheadler CM (2017) Pacing strategy during the final stage of a self-paced $V \mathrm{O}_{2 \max }$ (SPV) test does not affect maximal oxygen uptake. Eur J Appl Physiol. https://doi.org/10.1007/s00421-017-3656-3

Hogg JS, Hopker JG, Mauger AR (2015) The self-paced $V \mathrm{O}_{2 \max }$ test to assess maximal oxygen uptake in highly trained runners. Int J Sport Physiol Perform 10(2):172-177

Jenkins LA, Mauger A, Fisher J, Hopker J (2017a) Realiability and validity of a self-paced cardiopulmonary exercise test in post-MI patients. Int J Sports Med 38(4):300-306

Jenkins LA, Mauger AR, Hopker JG (2017b) Age differences in physiological responses to self-paced and incremental $\mathrm{VO}_{2 \max }$ testing. Eur J Appl Physiol. https://doi.org/10.1007/s00421-016-3508-6

Kirkeberg JM, Dalleck LC, Pettitt RW (2010) Validity of 3 protocols for verifying $V \mathrm{O}_{2 \max }$. Int J Sports Med 32(4):266-270

Lim W, Lambrick D, Mauger AR, Woolley B, Faulkner J (2016) The effect of trial familiarisation on the validity and reproducibility of a field-based self-paced $V \mathrm{O}_{2 \max }$ test. Biol Sport 33(3):269-275

Manoel F, de A, da Silva, de Lima DF, Machado JRP FA (2017) Peak velocity and its time limit are as good as the velocity associated with $V \mathrm{O}_{2 \max }$ for training prescription in runners. Sports Med Int Open 1(1):8-15

Mauger AR, Sculthorpe N (2012) A new $\mathrm{VO}_{2 \max }$ protocol allowing self-pacing in maximal incremental exercise. Br J Sports Med 46(1):59-63

Mauger AR, Metcalfe AJ, Taylor L, Castle PC (2013) The efficacy of the self-paced $V \mathrm{O}_{2 \max }$ test to measure maximal oxygen uptake in treadmill running. Appl Physiol Nutr Metab 38(2):1211-1216

Noakes TD (2008) Testing for maximum oxygen consumption has produced a brainless model of human exercise performance. Br J Sports Med 42(7):551-555

Nolan PB, Beaven ML, Dalleck L (2014) Comparison of intensities and rest periods for $V_{2} \mathrm{O}_{2 \max }$ verification testing procedures. Int $\mathrm{J}$ Sports Med 35(12):1024-1029

O'Brien BJ, Wibskov J, Knez WL, Paton CD, Harvey JT (2008) The effects of interval-exercise duration and intensity on oxygen consumption during treadmill running. J Sci Med Sport 11(3):287-90

Poole DC, Jones AM (2017) CORP: measurement of the maximal oxygen uptake $\left(V \mathrm{O}_{2 \max }\right): V \mathrm{O}_{2 \text { peak }}$ is no longer acceptable. $\mathrm{J}$ Appl Physiol 122(4):997-1002

Scheadler CM, Devor ST (2015) $\mathrm{VO}_{2 \max }$ measured with a self-selected work rate protocol on an automated treadmill. Med Sci Sports Exerc 47(10):2158-2165

Seiler KS, Sjursen JE (2002) Effect of work bout duration on physiological and perceptual responses to interval training in runners. Med Sci Sport Exerc 34(5):1613-1621

Smith TP, Coombes JS, Geraghty DP (2003) Optimising high-intensity treadmill training using the running speed at maximal $\left(\mathrm{O}_{2}\right)$ uptake and the time for which this can be maintained. Eur J Appl Physiol 89(3-4):337-343

Straub AM, Midgley AW, Zavorsky GS, Hillman AR (2014) Rampincremented and RPE-clamped test protocols elicit similar $V \mathrm{O}_{2 \max }$ values in trained cyclists. Eur J Appl Physiol 114(8):1581-1590

Swain DP, Franklin B (2002) $\mathrm{VO}_{2}$ reserve and the minimal intensity for improving cardiorespiratory fitness. Med Sci Sport Exerc 34(1):152-157

Yoon B-K, Kravitz L, Robergs $\mathrm{R}$ (2007) $V \mathrm{O}_{2 \max }$, protocol duration, and the $V \mathrm{O}_{2}$ plateau. Med Sci Sports Exerc 39(7):1186-1192 